\title{
Social-Cultural Environment and Performance of Donor Funded Health Projects in Kenya
}

\author{
Jones Ong'era Mobegi, \\ Dr. Rosemary James, \\ Dr. Paul Sang, \\ Department of Management Science, Kenyatta University
}

Doi:10.19044/esj.2020.v16n19p558 URL:http://dx.doi.org/10.19044/esj.2020.v16n19p558

\begin{abstract}
This study provides an empirical investigation on the effect of the social-cultural environment; local community literacy levels, support from local communities, language, and corruption levels on the performance of donor-funded health projects in Kenya. Empirical evidence indicates that most donor-funded health projects in Kenya experience time and cost overruns as well as quality issues. This study investigated a population of 69 donor-funded health projects that were initiated between 2008 and 2018 and were ongoing during the study period. A census study was conducted to ensure efficiency, representativeness, reliability, and flexibility since the population was small. The study adopted explanatory and descriptive research designs. Regression results indicated that language, support from the local communities, and the level of literacy in the local communities had positive relationships with the performance of donor-funded health projects in Kenya with coefficients of $0.021,0.045$, and 0.042 respectively. These factors were significant at a 5 percent significance level with p-values of 0.018, 0.019, and 0.047 respectively. Corruption levels had a negative relationship with the performance of donor-funded health projects in Kenya with a coefficient of 0.031 that was significant at a 5 percent significance level with a p-value of 0.013 . The study recommends that the government develops policies and frameworks that will help projects to minimize the negative effects of the social-cultural environment and enhance the positive effects, and that all decision-makers and other donor-funded health project stakeholders devise policies and strategies for controlling the effect of the social-cultural environment on the donor-funded health projects.
\end{abstract}

Keywords: Social-cultural, Environment, Performance, Donor, Funded, Projects 


\section{Introduction}

Donor funded health projects are a worldwide phenomenon with the developing countries being the greatest beneficiaries (Park, 2019). In Kenya, contributions to the health sector by donors have been on the increase, rising to 15 percent of the health budget in 2009/10 from 11 percent in 2005/06. The contribution of donors to the development budget of the Ministry of Health accounted for over 90 percent in some years. According to The Netherlands Enterprise Agency (2016) 57 percent of the MoH National Health Budget for Development was provided by Development Partners as of financial year 2014/15. Donor funds are used for varying health projects which include the construction of hospital buildings, capacity development, nutrition and care, provision of drugs and treated nets as well as fighting epidemics such as HIVAIDS and the Coronavirus (Covid-19).

Donor funded projects cover a wide range of areas which include health, water, and sanitation, agriculture, education, security, energy, infrastructure, and tourism. Kenya Vision 2030 in Sessional Paper 10 of 2012 identified flagship projects which are expected to directly address priorities in key sectors such as agriculture, education, health, water, and the environment. According to Vision 2030, health projects are critical to the attainment of all the other pillars of Vision 2030 because they ensure the availability of healthy and sufficient manpower. This points to the reason why both bilateral and multilateral donors have been increasing their support for the health projects over the years to the developing countries, especially Kenya (Mujabi, Otengei, Kasekende \& Ntayi, 2015).

The funding from donors to Kenya comes from both Official Donor Assistance (ODA) and Other Official Flow (OOF) sources and covers many areas which include education, infrastructure, health, investments, and even military support (Wexler, Valentine \& Kates, 2013). However, health captured an increasing share of all ODA (WHO, 2009), not just in Kenya but the world over from the start of the $21^{\text {st }}$ century. Donor funding for health and the number of funding organizations have grown dramatically in this period (Wexler et al., 2013). The ODA flows to Kenya in US dollars from the year 2000 to 2014 is as illustrated by figure 1.1 below. The Y-axis indicates the amounts of funding in dollars while the $\mathrm{X}$-axis indicates the years. 


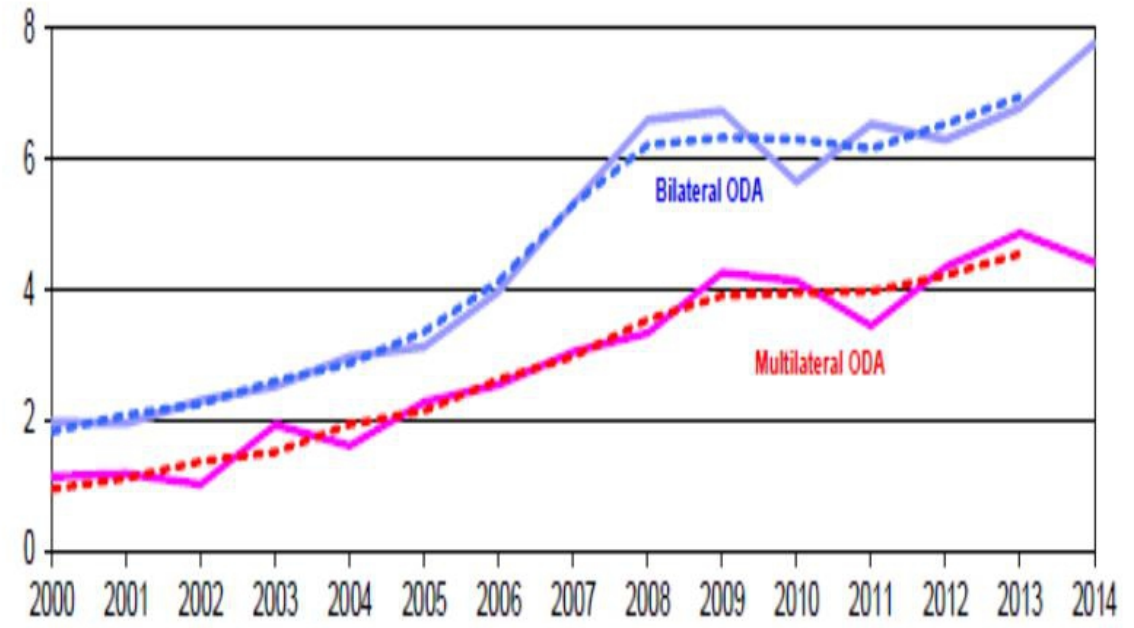

Figure 1.1: Total ODA USD Billion over 15 years

Source: Statistics from the Development Assistance Committee of the Organization for Economic Co-operation and Development

Many high-cost projects undertaken world over tend to have performance and sustainability challenges which are a concern for key donors including the Asian Development Bank, the World Bank, as well as bilateral aid agencies (Mugambi, 2014). According to Kiprop, Nzulwa, and Kwena (2017) little development has taken place in Sub-Sahara Africa despite donor funding for over half a century. High levels of unemployment, indebtedness, poverty, poor health, and poor economic performance are still prevalent in most of the sub-Saharan countries. Kiprop et al. (2017) recommend that due to the performance issues tagging the donor-funded projects, studies should be conducted to establish the challenges facing their implementation.

Projects in the health sector enable medical facilities to enhance their capacity to offer adequate and appropriate services to their clients. This is in terms of service quality, shorter waiting periods, quick responses to medical situations, and good customer service (WHO, 2019). Thus, good project performance is important if these objectives are to be achieved.

According to The Project Management Body of Knowledge (PMBOK) guide, project performance is measured in terms of budget or cost, time, and quality which are the three constraints of project performance (PMI, 2013, p. 1) as illustrated in figure 1.2. According to Gaturu and Muturi (2014) time is a critical factor and measure of project performance. The Bostock Marketing Group (BMG) Research (2015) also observed that budget and quality standards are critical measures of project performance. 


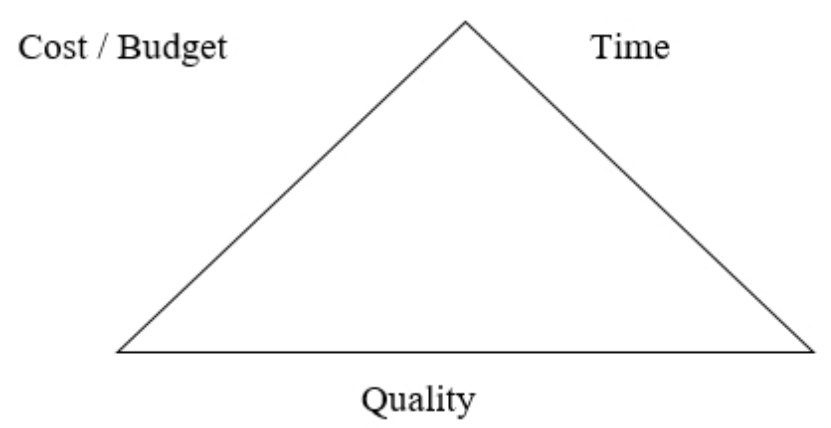

Figure 1.2: Project Performance Constraints Source; Project Management Institute, 2013

The performance of a project is good if it is completed within the planned timelines, cost, and quality. According to Anuar and Ng (2011) project completion within time and cost while maintaining quality is important for the success of projects. According to Stojcetovic, Lazarevic, Prlincevic, Stajcic, and Miletic ( 2013) cost, time, and quality are closely related. A change in one may affect others. Stojcetovic et al. (2013) argued that simply completing the project in time and within the cost is not enough without achieving the user's expected quality. This was supported by Al-Hajji and Zraunig (2018).

Time is an essential resource in the management of projects. It is irrecoverable, limited, and dynamic (Adeojo, 2012). It is a critical factor in the measurement of the performance of projects (PMI, 2013). Projects are time-bound and as such, during the project planning phase, a clear start and end time for the project should be determined (PMI, 2013). According to Mortaheb, Amini, Younesian, and Soltani (2012) the performance of projects is measured based on time. Memon, Rahman, and Azis (2012) also indicated that time performance is an important criterion for measuring the performance of projects.

The PMI (2013) suggested that the performance of a project is good if its progress against time is good. World over, many projects are experiencing time overruns. According to Memon et al. (2012) 79.5 percent of public projects and 66.25 percent of private projects experience time overruns in Malaysia. The 2017 edition of Deloitte Africa Construction report indicated that 87 percent of projects in Kenya experienced time overruns. Solis-Carcano, Corona-Suarez, and Garcia- Ibarra (2015) observed that prolonging the project execution time will result in cost overruns due to the extra expenses on materials, personnel, financial costs, and contract penalties. Memon et al. (2012) associated time overruns to both internal and external factors. Akanni, 
Oke and Akpomiemie (2014) identified social-cultural factors among the external factors.

Cost is a measure of the total of what has been spent on the project to the current level. It is dynamic and not static ( Adeojo, 2012). According to PMI (2013) cost is one of the measures of the performance of projects alongside time and quality. Memon et al. (2012) concurs that cost is a critical measure of the performance of a project. In Malaysia, 53.2 percent of public projects and 62.8 percent of private projects experience cost overruns with an overrun of between $5-10$ percent of project cost (Memon et al., 2012). In Kenya, 48 percent of the projects experience cost overruns (Labuschagne, 2017). Cost overruns are caused by inflation on materials (Olawale \& Sun, 2018), time overruns ( Solis-Carcano et al., 2015) and rework (Hwang, Thomas \& Haas, 2009). This study investigated the effect of the social-cultural environment on the cost measure of performance.

Every project has an anticipated level of quality based on the details and specifications set out by the users (Stojcetovic et al., 2013). According to Anuar and $\mathrm{Ng}$ (2011) quality performance is concerned with the quality of the project's outcome and the quality objectives of the project. Mortaheb et al. (2012) observed that a project outcome has quality if it satisfies the client's overall expectations and if it achieves the technical specifications. Quality is a key measure of the performance of a project. The quality of a project is affected by lack of knowledge and skills to transform ideas into quality outcomes (Anuar \& Ng, 2011), lack of understanding on quality expectations and the newness and uniqueness of the project ( Stojcetovic et al., 2014), and project risks (Aller, 2016).

The performance of donor-funded health projects is affected by different factors across projects and countries. Thiele (2016) observed that both micro and macro environments affect project performance. The macroenvironment comprises of the political, legal, technological, economic, socialcultural, and physical factors. Akanni et al. (2014) observed that the socialcultural environment consists of customs, lifestyles, and values that characterize a society. Further, the researchers opined that population demographics, rising educational levels, norms and values, language, and attitudes toward social responsibilities are examples of socio-cultural variables. Musa, Amirudin, Sofield \& Musa (2015) observed that social factors concern culture, health consideration, and the general lifestyle of people. According to Gudiéne, Banaitis and Banaitiené (2013) social factors include cultural issues, health considerations, and the general lifestyle of people. These variables have the potential to affect organizations that operate 
within society. Community hostilities towards a medical initiative will, for example, hinder the uptake and success of the project.

Endemic corruption and poor reporting structures in the public sector in Kenya are causes of delays in donor-funded health projects (Department for International Development (DFID), 2012). Gaturu and Muturi (2014) observed that delays plague the delivery of donor-funded projects in many developing countries. The consistent delays in the completion of projects and cost overruns in Kenya just like in most parts of the developing world call for research to determine the factors that are causing poor project performance.

\section{Statement of the problem}

Kenya's vision 2030 identified health as a key factor in the attainment of the vision objectives. This explains the many donor-funded projects implemented in the country's health sector from the start of the $21^{\text {st }}$ century. However, the Wolfensohn Center for Development working paper 8 of 2009 observed that donor funding has not produced the desired results in Kenya (Mwega, 2009). The poor performance of health projects dates back to the 1950s (Ika, Diallo \& Thuillier, 2011). According to Muchungu (2011) 58 percent of donor-funded projects in Kenya showed poor performance as measured by time, budget, scope, and client satisfaction. According to the 2017 edition of Deloitte Africa report, approximately 48 percent of all projects reported cost overruns and 87 percent of the projects had a time overrun in Kenya. Endemic corruption and poor reporting structures in the public sector in Kenya are causes of delays in donor-funded health projects (DFID, 2012). Further, Kirui \& Moronge (2016) found out that many health projects initiated in Bomet County had stalled. Gitonga and Keiyoro (2017) also found out that health grants were not utilized well in the implementation of health care projects in Meru County due to corruption. The study by Kirui and Moronge (2016) recommended that further studies should be carried out to determine the effects of corruption on the performance of health projects in Kenya.

According to the Independent Commission for Aid Impact (ICAI, 2014) DFID programmes underperformed as compared to the global and regional averages since the level of child mortality in Kenya remained high. ICAI (2014) further observed that the Global Fund's monitoring system judged the performance of the main grant for malaria to Kenya during the period 2013 - 14 as below expectations. An independent donor review concluded that the delays for implementation of Global Fund grants in Kenya typically ranged between 6 and 24 months (ICAI, 2014) implying that the projects failed.

After an extensive study of the struggling donor-funded health projects in Kenya, reasons for the poor performance of the projects need to be determined. This is to ensure the projects perform well and that they achieve 
their objectives of ensuring a healthy nation. In this regard, the study sought to find out the effect of the social-cultural factors; community literacy levels, community support, language, and corruption levels on the performance of donor-funded health projects in Kenya through the following research objectives.

i) To determine the effect of community literacy levels on the performance of donor-funded health projects in Kenya

ii) To establish the effect of community support on the performance of donor-funded health projects in Kenya

iii) To find out the effect of language on the performance of donorfunded health projects in Kenya

iv) To investigate the effect of corruption levels on the performance of donor-funded health projects in Kenya

\section{Literature Review Theoretical Review}

The study was underpinned on the theory of constraints, Hofstede's cultural dimensions theory, and the goal setting theory. The theory of constraints was developed by Dr. Eliyahu M. Goldratt in his 1984 book "The Goal". According to the theory, a very small number of constraints limit any manageable system in achieving more of its goals (Chowdhary, 2009). The attainment of project goals is affected by both internal and external constraints. If these constraints are not managed well, projects are bound to fail (Kisilu, Kiarie \& Munyao, 2016). The theory provides for ways of identifying the key factors that limit (constrain) the achievement of goals. It also provides for ways of ensuring that the constraint is not a limiting factor by improving it in a well-organized manner. Kiprop, et al. (2017), and Maina \& Gathenya (2014) suggested that the overall performance of a project could be improved by focusing on fixing the main problem (constraint).

Hofstede's cultural dimensions theory was devised by Geert Hofstede in 1993 (Anastasia, 2015). It establishes a framework circling cross-cultural communication which collectively portrays the impact of the culture established in society on the values of the society members. This model is used to explain organizational behaviours based on six entirely different dimensions which are; job-oriented versus employee-oriented, processoriented versus results-oriented, professional versus parochial, tight versus loose control, open systems versus closed systems, and pragmatic versus normative (Hofstede, 2011). Hofstede also indicated that cultures can change their position on a dimension within the dimensional model. The author further observed that technological modernization is an important force toward culture change, despite there being not the slightest proof that it wipes out the 
variety on other dimensions. It leads to partly similar developments in different societies (Hofstede, 2011).

The goal setting theory was developed by Edwin Locke and Gary Latham in 1990 to provide a basis for employee motivation in organizations (Lunenburg, 2011). It emphasizes the importance of the relationship between goals and performance. The theory further indicates that when goals are specific and challenging the most effective performance will result (Lunenburg, 2011). Projects are designed with specific cost, time, and quality objectives in mind. The attainment of these objectives results in a good performance for the project. However, the attainment of the project goals faces several external and internal environment constraints (PMI, 2013). The external environment constraints are economic, social-cultural, technological, political, legal, and environmental. The theory of constraint provides a good base for determining the most limiting constraint to the attainment of project goals. This base was applied in this study to determine the effect of the socialcultural environment on the performance of donor-funded health projects in Kenya.

\section{Empirical Review}

Most developing countries experience generally low literacy levels. In Guatemala, just like in many developing countries there are pockets of very high illiteracy among the poor and mainly indigenous rural populations, for example, only 30 percent of Mayan women are literate (Catholic Relief Services, Guatemala Education Team, 2020). Kenya's literacy level in 2018 was 81.5 percent (World Data Atlas, 2020). However, the country has some pockets of very high illiteracy levels, such as the North Eastern, part of the Rift Valley, and in the informal settlements. Literacy levels measure the percentage of the population aged 15 and above who can, with understanding, read, and write a short simple statement on their everyday life. It also encompasses numeracy. Levels of community literacy affect communication and the instruction process thus affecting the performance of projects.

For a community development project to succeed, it must have the support of its community from the start (Community Development at the ST Louis FED, 2020). Community-Based Health Volunteers (CBHVs) in Ghana are affected by situations where they are not getting the needed support from community members (Chatio, Welaga, Tabong \& Akweongo, 2019). The lack of community support on a project will affect the morale of the project team hence affecting the performance of projects negatively (Chatio et al., 2019). Akanni et al. (2014) observed that youth restiveness, attacks on construction workers especially the kidnapping of expatriates and militancy were key social factors that affected the performance of building projects in Nigeria. 
Teams of global projects and those run by international donors face challenges in physical distance, cultural diversity, and language barriers (Lima $\&$ Patah, 2016). The communication barriers are magnified in global teams by virtual distance, by cultural diversity and by language (Anantatmula \& Thomas, 2010). Language barriers may lead to misunderstandings, relationship difficulties, and poor communication. According to Lin, Chen, and Song (2012) in multicultural interactions related to work, there may be difficulties concerning language and communication. Further, Akanni et al. (2014) observed that language had a significant effect on building projects in Nigeria as the illiterate building workers developed "Pidgin English" which was an adulterated form of English that they used for communication among them.

Various international assessments continue to rank Kenya as one of the most corrupt countries in the world and Kenyans themselves cite corruption as an issue of major concern for them (World Bank, 2009b; Transparency International, 2018). According to Damoah, Akwei, Amoako, Botchie (2018) and (DFID, 2015) corrupt practices, include bribery of local or foreign government officials and private companies, "facilitation of payments," fraud, embezzlement, theft, collusion, extortion, patronage clientelism, nepotism, and rent seeking. There are numerous instances of corruption in aid projects (DFID, 2015). Theft, embezzlement, and fraud by public officials reduce the availability of funds for development-related activities (Hope, 2014). Corruption causes government projects' failure (Damoah et al., 2018). At the project management level, corruption pauses a direct effect, while at the product stage, corruption pauses an indirect effect. Akanni et al. (2014) observed that groups of unemployed youth often demanded for illegal fees popularly known as "settlement" from constructors which caused delays ranging from days to weeks on construction activities.

\section{Research Methodology}

This study applied explanatory and descriptive research designs. The combined designs have the potential to offer a more robust research (Caruth, 2013). A combination of explanatory and descriptive research designs will provide more insights into the subject of investigation and capture information that could have been left out when using only one study design. While the descriptive research seeks to answer the question "what is going on?" explanatory research will answer the question "why is it going on? This will enable the researcher to simultaneously understand mechanisms, explore associations, and document risks (Morse \& Niehaus, 2016). Explanatory research will not just describe, but explain the phenomena being studied (Given, 2008). 
To analyse the data collected on the social-cultural environment and the performance of donor-funded health projects to determine the relationship between them, a regression model was used as suggested by Muthen and Muthen (2012) who observed that for continuous outcome variables linear regression models will be applied. This model is suitable for this study since performance is a continuous variable. The empirical model is;

$$
Y=\beta_{0}+\beta_{1} X_{1}+\beta_{2} X_{2}+\beta_{3} X_{3}+\beta_{4} X_{4}+\mu_{i}
$$

Where $\beta_{0}$ is a constant, $\beta_{1}, \beta_{2}, \beta_{3}, \beta_{4}$ are coefficients of the social-cultural factors, $X_{1}$ is community literacy level, $X_{2}$ is community support, $X_{3}$ is Language and $X_{4}$ is corruption level and $\mu_{i}$ is the error term.

The study focused on a population of 69 donor-funded health projects that were initiated between 2008 and 2018 and were ongoing during the study period. Since the population in the study was small, a census study of the 69 donor-funded health projects in Kenya was conducted to ensure the study meets efficiency, representativeness, reliability, and flexibility requirements (Saunders, Lewis, and Thornhill, 2012). Data was collected by the use of a semi-structured questionnaire. The questionnaire was made up of open and closed-ended questions with some of them being measured on a Likert scale of 1-5. The questionnaire was broken into sections with each section collecting data for a specific parameter. Part A of the questionnaire was used to collect data on the identification of the projects and the respondent's background information. Part B collected data on the health project's key performance indicators. Part C, D, E, and F of the questionnaire collected data on the effect of the social-cultural factors; language, support from local communities, local community literacy levels, and corruption levels on the performance of donorfunded health projects. Saunders et al. (2012) observes that in a questionnaire research, objectives are translated into specific questions whose answers provide data for hypothesis testing. A questionnaire allows for the collection of data from large samples, has no bias, upholds confidentiality, and saves time.

Descriptive and inferential statistics with the aid of the Statistical Package for Social Sciences (SPSS) version 20.0 was used to analyse quantitative data. This involved the computation of mean scores, frequencies, percentages, standard deviations, and variances (Berenson et al., 2013). Correlation analysis was conducted to determine the strength of the relationship between the predictor and the predicted variables. To determine the relationship between the predictor and predicted variables, multiple regression analysis was applied since the study's model has many predictor variables and one possible outcome. 


\section{Research findings and discussions Descriptive statistics}

The social-cultural environment factors investigated were; level of literacy in the community, support from the local communities on the project, language, and corruption levels in the running of the projects. The findings were analysed as in table 1.1 below.

Table 1.1: Social-cultural Environment

\begin{tabular}{|c|r|r|r|}
\hline Variables & $\mathbf{N}$ & Mean & Std. Deviation \\
\hline Community literacy level & 42 & 2.48 & 1.330 \\
\hline Community support & 42 & 2.33 & 1.337 \\
\hline Language & 42 & 2.05 & 1.287 \\
\hline Corruption levels & 39 & 1.64 & 1.266 \\
\hline Overall & & $\mathbf{2 . 1 2 5}$ & $\mathbf{1 . 3 0 5}$ \\
\hline
\end{tabular}

Source: (Survey data, 2019)

From the study, all the four social-cultural variables; the level of literacy in the local community, support from the local community on the project, language, and corruption levels had low means of 2.48, 2.33, 2.05, and 1.64 respectively. These low means imply a low effect of each of the social-cultural factors on the performance of the donor-funded health projects in Kenya. The level of support from the local community on the project had the highest standard deviation of 1.337 followed by the level of literacy in the local community at 1.330 , while corruption levels had the least variability with a standard deviation of 1.266. Overall, the social-cultural environment had a mean of 2.125 which implies that the respondents agreed to a low extent that the social-cultural environment affected the performance of donor-funded health projects. The analysis also determined a mean standard deviation of 1.305 which implies a low variability of the collected data from the mean.

Although most of the respondents indicated that corruption had the least effect on the performance of the donor-funded health projects in Kenya, the Transparency International index of 28 out of 100 for Kenya places the country as one of the highly affected by corruption (Transparency International, 2018). According to Eldridge and Tekolste (2016) the low corruption levels reported in this study may have been due to the results-based financing approaches taken by the donors, where the donor only disburses more funds when the agreed results have been achieved.

The respondents who rated the effect of social-cultural factors on the performance of donor-funded health projects as low and very low held that; the community was very receptive and participated in the project activities, majority of the community members were literate and aware of development issues, community priority to implement projects is low and there is an indirect contact between the donors and the community members. On corruption, most 
respondents attributed the low levels of corruption to the stringent controls by the donors on the disbursement of donations such as the direct payment for goods and services by the donors rather than the provision of funds to the Kenyan government to procure the goods and services. Those who rated social-cultural environment high and very high held that norms and beliefs affected testing and usage of HIV/AIDs drugs, some counties required translators who may not translate well and language barrier between community members and the outsider personnel implementing the project.

\section{Regression Analysis}

Socio-cultural factors were regressed against the performance of donor-funded health projects in Kenya. The findings were as shown in table 1.2 below.

Table 1.2: Model Summary

\begin{tabular}{|c|c|c|c|c|}
\hline \multicolumn{5}{|c|}{ Model Summary } \\
\hline Model & $\mathrm{R}$ & R Square & Adjusted R Square & $\begin{array}{l}\text { Std. Error of the } \\
\text { Estimate }\end{array}$ \\
\hline 1 & $.605 a$ & .366 & .316 & .57092 \\
\hline
\end{tabular}

a. Predictors: (Constant), Level of literacy, Language, support from the local community and corruption levels

Source: (Survey data 2019)

The model summary indicates that a socio-cultural environment comprising of the level of literacy in the local community, support from the local community, language, and corruption levels had a moderate correlation with the performance of donor-funded health projects with an $R=0.605$. The model further indicated that the social-cultural environment explained 36.6 percent of the variation in the performance of the donor-funded health projects.

The model significance was tested and found significant at a 5 percent significance level $(\mathrm{P}$-value $=0.00<0.05)$. The results are as in table 1.3 below.

Table 1.3: Model Significance

\begin{tabular}{|c|c|c|c|c|c|c|}
\hline \multicolumn{7}{|c|}{ ANOVA $^{\mathrm{a}}$} \\
\hline \multicolumn{2}{|c|}{ Model } & Sum of Squares & Df & Mean Square & $\mathrm{F}$ & Sig. \\
\hline \multirow[t]{3}{*}{1} & Regression & .529 & 3 & .176 & .467 & $.000^{\mathrm{b}}$ \\
\hline & Residual & 14.344 & 38 & .377 & & \\
\hline & Total & 14.873 & 41 & & & \\
\hline \multicolumn{7}{|c|}{ a. Dependent Variable: $Y$} \\
\hline \multicolumn{7}{|c|}{$\begin{array}{l}\text { b. Predictors: (Constant), Level of literacy in the local community, Language, support from the } \\
\text { local community on the project and level of corruption }\end{array}$} \\
\hline
\end{tabular}

Source: (Survey data 2019)

The social-cultural factors were regressed against the performance of donorfunded health projects and the results were presented as in table 1.4 below. 
Table 1.4: Regression results

\begin{tabular}{|c|c|c|c|c|c|c|}
\hline \multicolumn{7}{|c|}{ Coefficients $^{\mathrm{a}}$} \\
\hline \multirow{2}{*}{\multicolumn{2}{|c|}{ Model }} & \multicolumn{2}{|c|}{$\begin{array}{l}\text { Unstandardized } \\
\text { Coefficients }\end{array}$} & \multirow{2}{*}{$\begin{array}{c}\begin{array}{c}\text { Standardize } \\
\mathrm{d} \\
\text { Coefficients }\end{array} \\
\text { Beta } \\
\end{array}$} & \multirow[b]{2}{*}{$\mathrm{T}$} & \multirow[b]{2}{*}{ Sig. } \\
\hline & & B & Std. Error & & & \\
\hline \multirow[t]{4}{*}{1} & (Constant) & 3.758 & .042 & & 89.292 & .000 \\
\hline & Language & .021 & .009 & .045 & 2.232 & .018 \\
\hline & $\begin{array}{l}\text { Support from the local } \\
\text { community }\end{array}$ & .045 & .019 & .101 & 2.340 & .019 \\
\hline & $\begin{array}{l}\text { Level of literacy in } \\
\text { the local community }\end{array}$ & .042 & .021 & .093 & 1.992 & .047 \\
\hline & Corruption levels & -.031 & .015 & -.093 & -2.131 & .013 \\
\hline \multicolumn{7}{|c|}{ a. Dependent Variable: Y } \\
\hline
\end{tabular}

Source: (Survey data, 2019)

The model had a positive constant of 3.758, which was significant at 5 percent significance level $(\mathrm{t}=89.292 ; \mathrm{P}$-value $=0.000<0.05)$. Language indicated a positive relationship with performance as indicated by the coefficient of 0.021 . This relationship was significant at 5 percent significance level ( $\mathrm{p}$-value $=0.018<0.05$ ). Support from the local community on the project had a positive effect on performance as shown by the coefficient of 0.045 . The relationship was significant at 5 percent significance level $(\mathrm{t}=2.340$; $\mathrm{P}$-value $=0.019<0.05)$. Similarly, the level of literacy in the local community indicated a positive relationship with performance as shown by the regression coefficients of 0.042 . The relationship was also significant at 5 percent significance level $(\mathrm{t}=1.992 ; \mathrm{P}$-value $=0.047<0.05)$. Corruption levels in the project had a negative relationship with the performance of donor-funded health projects as indicated by the coefficient of -0.031 . This factor was found to be significant at 5 percent significance level $(\mathrm{t}=-2.131 ; \mathrm{P}$-value $=$ $0.013<0.05)$.

The regression model developed between the social-cultural factors and the performance of donor-funded health projects in Kenya was as below.

$$
Y=3.758+0.021 X_{1}+0.045 X_{2}+0.042 X_{3}-0.031 X_{4}+\mu_{i}
$$

This indicates that there is a positive relationship between all the independent variables and the dependent variable except for corruption levels which had a negative relationship. The implications of this are that as more and more people in the local communities learn to speak and write in the Kenyan national languages (English and Kiswahili) communication gets enhanced leading to improved performance of the donor-funded health projects. Moreover, as the level of support and level of literacy from the local communities improve, the performance of donor-funded health projects is also expected to improve. On the other hand, as corruption levels increase, the 
performance of the donor-funded health projects will decrease, and vice versa. In all, support from the local community had the highest effect as indicated by a $\beta$ value of 0.045 on the performance of the donor-funded health projects while language had the least effect as indicated by a $\beta$ value of 0.021 .

These findings concur with the findings of Akanni et al. (2014) and Musa et al. (2015) that social-cultural factors have a significant effect on the performance of construction projects in the Delta State, Nigeria and that the social-cultural factors are significantly related to public housing project success respectively.

\section{Summary, Conclusions, and Recommendations Summary}

The effect of the social-cultural factors on the performance of donorfunded health projects was tested using the language, support from the local communities, literacy levels of the local communities, and corruption levels on the project as variables. Descriptive statistics of this study determined that overall, the social-cultural environment has a low effect on the performance of donor-funded health projects as shown by the mean of 2.125 . The means obtained for each of the social-cultural variables were $2.05,2.33,2.48$, and 1.64 for language, support from local communities, literacy levels of the local communities, and corruption levels respectively. The reasons for the low effect as provided by the responses received were that the communities were very receptive and participative in the projects, the majority of the community members were literate and aware of development issues and there was a low and indirect association between the donors and the community members. The respondents who rated the effect of the social-cultural variables on the performance of donor-funded health projects in Kenya as high and very high held that norms and beliefs affected testing and usage of HIV/AIDs drugs, some counties required translators who may not have translated well and the language barrier between community members and the personnel implementing the project.

The regression analysis indicated that there was a significant positive relationship between the social-cultural environment and the performance of donor-funded health projects in Kenya. Regression results indicated that language, support from the local communities, and the level of literacy in the local communities with coefficients of $0.021,0.045$, and 0.042 respectively had positive relationships with the performance of donor-funded health projects in Kenya. These factors were significant at a 5 percent significance level with $\mathrm{p}$ values of $0.018,0.019$, and 0.047 respectively. Corruption levels had a negative relationship with the performance of donor-funded health projects in Kenya with a coefficient of -0.031 that was significant at a 5 percent significance level with a p-value of 0.013 . 


\section{Conclusion}

The regression analysis undertaken in this study indicated that the social-cultural environment had a significant positive relationship with the performance of donor-funded health projects. If the social-cultural environment is improved, the performance of the donor-funded health projects will also improve. On the contrary, if the social-cultural environment deteriorates, the performance of the donor-funded health projects will also deteriorate. Language plays a vital role in communication in projects. It can be a barrier to effective communication. To enhance communication, project teams and project stakeholders should learn the official languages of Kenya; English and Kiswahili.

The local community literacy level has a positive relationship with the performance of donor-funded health projects in Kenya. The education and training systems in Kenya should be enhanced to ensure an improvement in the literacy level of the communities. This will make the sharing of instructions among the project participants good thereby positively affecting the outcomes of the donor-funded health projects in Kenya. Furthermore, an increase in the support accorded to projects by the local communities will enhance the performance of the donor-funded health projects. The government of Kenya should mobilize the communities to support the donor-funded health projects through the provision of required resources and to actively participate in the implementation of the projects. A reduction in corruption levels would increase the performance of donor-funded health projects while an increase in corruption levels will decrease the performance of donor-funded health projects. Project managers must ensure that project resources are used for the intended purpose if the objectives of the donor-funded health projects are to be achieved. Based on the effects of each of the above factors, this study concluded that the social-cultural environment has a positive significant effect on the performance of donor-funded health projects in Kenya.

\section{Recommendations}

The study recommends that the government of Kenya should develop policies and frameworks that will minimize the negative effects of the socialcultural environment; language, local community literacy levels, support from the local community, and corruption levels on the performance of donorfunded health projects and enhance the positive effects. The study also recommends that all decision-makers and other donor-funded health project stakeholders devise strategies for enhancing the performance of the projects within their social-cultural environments.

The government should create a platform to enable the local communities to learn English and Kiswahili which are the national languages in Kenya. This can be achieved by enhancing adult education as well as the 
provision of free primary and secondary education. Besides, local communities can be motivated to participate in the projects by providing them with information on the projects, as well as alleviating fears on the possible outcomes of participating in the projects. Furthermore, the government should put in place mechanisms for dealing with corruption in donor-funded health projects. These mechanisms may include; developing proper resource utilization and reporting structures, project control mechanisms as well as putting in place punitive measures to be meted on offenders to deter those who may be interested in misappropriating project resources.

\section{References:}

1. Adeojo, L.A., (2012). Effective Time Management for High Performance in an Organization. Thesis, Seinajoki University of Applied Sciences.

2. Akanni, P.O., Oke, A. E., \& Akpomiemie, A. O. (2014). Impact of environmental factors on building project performance in Delta State, Nigeria. Housing and Building National Research Center, 91 - 97.

3. Al-Hajji, A. \& Zraunig, M.M. (2018). The Impact of Project Management Implementation on the Successful Completion of Projects in Construction. International Journal of Innovation, Management, and Technology, Vol9. No.1

4. Aller, C. M., (2016). Determining the Success of Innovative Projects using Performance and Complexity Indicators. Bachelor Thesis, Turku.

https://www.theseus.fi/bitstream/handle/10024/114612

5. Anantatmula, V. \& Thomas, M. (2010). Managing Global Projects: A Structured Approach for Better Performance. Project Management Journal, 41(2), 60 - 72.

6. Anastasia. (2015, September 04). Understanding Cultures \& People with Hofstede Dimensions. Retrieved January 28th, 2017, from Cleverism: www.cleverism.com

7. Anuar, N. I., \& Ng, P. K., (2011). The Role of Time, Cost, and Quality in Project Management. IEEE International Conference on Industrial Engineering and Engineering Management. Singapore. ResearchGate.

8. Berenson, M.L., Levine, D.M., Krehbiel, T.C., Stephan, D., O'Brien, M., Jayne, N. \& Watson, J.(2013).Basic Statistics, $3^{\text {rd }}$ Edition. Melbourne: Pearson.

9. Bostock Marketing Group Research. (2015). Factors in Project Success. The Association for Project Management (APM). www.bmgresearch.co.ke 
10. Caruth, G. D. (2013). Demystifying Mixed Methods Research Design. Mevlana International Journal of Education: A Review of the Literature, 112 - 122.

11. Catholic Relief Services, Guatemala Education Team, (2020, April 9th). Integrated Community Literacy for Development. Retrieved from Catholic Relief Services: https://www.crs.org/sites/default/files/toolsresearch/how-to-guide-integrated-community-literacydevelopment.pdf

12. Chatio, S., Welaga, P., Tabong, P.T. \& Akweongo, P. (2019). Factors influencing the performance of community-based health volunteers' activities in the Kassena-Nankana Districts of Northern Ghana. PLOS ONE.

13. Chowdhary, M. (2009). Constraint Management, Throughput, Operating Expenses, and Inventory. New Delhi: Global India Publications PVT Ltd.

14. Community Development at the ST Louis FED, (2020, April 8th). Five Principles for Launching a Successful Community Development Initiative. Retrieved from Coming up with the Money:https://www.stlouisfed.org/ /media/files/pdfs/communitydev elopment/comingupwithmoney/launching_successful_community_de velopment_initiative.pdf?la=en

15. Damoah, I.S, Akwei, C.A, Amoako, I.O \& Botchie, D. (2018). Corruption as a Source of Government Project Failure in Developing Countries: Evidence from Ghana. Project Management Journal, 17 - 33.

16. Deloitte Africa Construction Report. (2017). Africa Construction Trends Report.

17. Department for International Development (DFID), (2015). Why Corruption Matters: Understanding Causes, Effects, and How to Address Them (Evidence Paper on Corruption). Department of International Development.

18. Eldridge, M \& Tekolste, R. (2016). Results-Based Finance Approaches. Urban Institute. https:

www.urban.org/sites/default/files/publication/85601/results-basedfinancing-approaches.pdf

19. Gaturu, S.N. \& Muturi, W. (2014). Factors Affecting the timeliness of Completion of Donor Funded Projects in Kenya: A Case of World Agroforestry Centre (ICRAF). European Journal of Business Management, 189 - 202.

20. Gitonga, Z. \& Keiyoro, P. (2017). Factors Influencing the Implementation of HealthcareProjects: The Case of Meru County, 
Kenya. International Academic Journals of Information Sciences and Project Management, Volume 2, Issue 1 pp 259 - 280

21. Given, L. M. (2008). Explanatory Research. The SAGE Encyclopedia of Qualitative Research Methods.Sage

22. Gudiéne, N., Banaitis, A \& Banaitiené, N.(2013). Evaluation of Critical Success Factors for Construction Projects-an Empirical Study in Lithuania. International Journal of Strategic Property Management, $21-31$

23. Hofstede, G. (2011). Dimensionalizing Cultures: The Hofstede Model. Online Readings in Psychology and Culture, p. Article 8.

24. Hope, K. R. (2014). Kenya's Corruption Problem: Causes and Consequences. Commonwealth \& Comparative Politics, 493 -512.

25. Hwang, B. \& Thomas, S. R., \& Haas, C., (2009). Measuring the Impact of Rework on Construction Cost Performance. Journal of Construction Engineering and Management- ASCE - J Constr Eng Manage-ASCE. 135. 10.1061/(ASCE)0733-9364(2009)135:3(187).

26. Ika, L. A., Diallo, A. \& Thuillier, D. (2011). Critical Success Factors for World Bank Projects: An Empirical Investigation. International Journal of Project Management, 105 - 116.

27. Independent Commission for Aid Impact (ICAI), I. C. (2014). DFID's Contribution to the Reduction of Child Mortality in Kenya. ICAI.

28. Kiprop, D., Nzulwa J. \& Kwena, R. (2017). Challenges facing donorfunded projects in Kenya: A case of Community Empowerment and institutional support project. The Strategic Journal of Business and Change Management, 278 - 294.

29. Kirui, D.K. \& Moronge, M. (2016). Drivers of Performance of Devolved Health Projects in Kenya: A Case of Bomet County. The Strategic Journal of Business and Change Management, pp 227250

30. Kisilu, R. N., Kiarie.D., Munyao, A. (2016). Determinants of Successful Completion of Donor Funded Projects in Kenya: A Case of Turkana County.The Strategic Journal of Business and Change Management, 651-671.

31. Labuschagne, J-P, (2017), Africa Construction Trend Report. Available at file:///C:/Users/Lec/Downloads/africa-constrreport-2018.pdf. Accessed on 11.04.2018

32. Lima, N. \& Patah, L.A. (2016). Cultural Issue and its Influence in the Management of Global Project. Future Studies Research Journal, 90 112. 
33. Lin, Y., Chen, A.S., and Song, Y. (2012). Does Your Intelligence Help to Survive in a Foreign Jungle? The Effects of Cultural Intelligence and Emotional Intelligence on Cross-cultural Adjustment. International Journal of Intercultural Relations, 36(4), 541-552.

34. Lunenburg, F. C. (2011). Goal-Setting Theory of Motivation. International Journal of Management, Business, and Administration, Vol 15.

35. Maina, C. \& Gathenya, J., (2014). Influence of Economic Factors on Performance of Project Management among Petroleum Marketing Firms in Kenya. International Journal of Academic Research in Business and Social Sciences, Vol 4, No.6.

36. Memon, A.H., Rahman, I.A., Azis, A.A.A., (2012). Time and Cost Performance in Construction Projects in the Southern and Central Regions of Penisular Malaysia. International Journal of Advances in Applied Sciences. Pp 45 - 52

37. Mortaheb, M. M., Amini, Y., Younesian, A. H., \& Soltani, P., (2012). Impacts of Engineering Work Quality on Project Success. $26^{\text {th }}$ IPMA World Congress, Crete, Greece. Elsevier Ltd. PP 429 - 437.

38. Muchungu, P. K. (2011). The Contribution of Human Factors in the Performance of Construction Projects in Kenya: A Case Study of Construction Project Team Participants in Nairobi. Dissertation. Nairobi, Kenya: University of Nairobi.

39. Mugambi, M.D.,(2014). University of Nairobi e-repository. Retrieved September 9, 2017, from;

http://erepository.uonbi.ac.ke/bitstream/handle/11295/97870/Miriti

40. Mujabi, S., Otengei, S.O., Kasekende, F. \&Ntayi, J.M. (2015) Determinants of Successful Implementation of Donor Funded Projects in Uganda. International Journal of Social Economics, Vol. 42 Issue: 12, pp.1139-1154

41. Musa, M.M., Amirudin, R., Sofield, T.\& Musa, M.A. (2015). Influence of External Environmental Factors on the Success of Public Housing Projects in Developing countries. Construction Economics and Building, Vol 15, No. 4.

42. Muthen, L.K, and Muthen, B.O. (1998 - 2012). Mplus User's Guide. Seventh Edition, Los Angeles, CA

43. Mwega F.M, (2009). A Case of Aid Effectiveness in Kenya; Volatility and Fragmentation of Foreign Aid with a Focus on Health. Available onhttps://www.brookings.edu/wpcontent/uploads/2016/06/01_kenya_aid_mwega.pdf. Accessed on 11.04.2018

44. Morse, J.M. \& Niehaus, L. (2016). Mixed Method Design. Principles and Procedures. London; Routledge, Taylor \& Francis Group. 
45. Olawale, Y. A. \& Sun, M., ( 2018). Cost and Time Control of Construction Projects: Inhibiting Factors and Mitigating Measures in Practice.

46. Park, J. D. (2019). Assessing the role of Foreign Aid, Donors, and Recipients. In: Re-inventing Africa's Development. Palgrave Macmillan Cham.

47. PMI. (2013). A Guide to the Project Management Body of Knowledge ( PMBOK, Guide), Fifth Edition. Project Management Institute.

48. Saunders, M. N. K., Lewis, P. \& Thorn hill, A. (2012).Research methods for business students, $\quad 6^{\text {th }}$ edition, Harlow, England: Pearson Education.

49. Solis-Carcano, R. G., Corona-Suarez, G.A., Garcia-Ibarra, A.J.,(2015). The Use of Project Time Management Processes and the Schedule Performance of Construction Projects in Mexico. Journal of Construction Engineering.

50. Stojcetovic, B., Lazarevic, D., Prlincevic B., Stajcic D., \& Miletic S., (May 2014). Project Management: Cost, Time and Quality. 8th International Quality Conference. ResearchGate.

51. The Netherlands Enterprise Agency, (2016). Kenya Healthcare Sector Opportunities for the Dutch Life Sciences \& Health Sector. Nairobi

52. Thiele, M. T. (2016). Factors influencing the performance and sustainability of integrated Coastal management projects in the Philippines: An evaluation of the World Bank Central Visayasregional project (CVRP) 1984-1992. Retrieved 09 30, 2016, from http://nsgl.gso.uri.edu

53. Transparency International. (2018). Corruption Perceptions Index 2017. Transparency International Kenya. Retrieved 03 17,2019 from https://tikenya.org/wp-content/uploads/2018/02/CorruptionPerceptions-Index-2017.pdf

54. Wexler, A., Valentine A . \& Kates, (2013, January). US Global Health Policy, Donor Funding for Health in Low \& Middle Income Countries 2002 - 2010. Retrieved September 24, 2017, from The Henry J Kaiser Family Foundation: http://www.who.int/workforcealliance/knowledge/resources/KFF_Jan 2013.pdf

55. World Bank, (2009b). Kenya poverty and inequality assessment: Executive summary (Report No. 44190-KE). Washington DC: World bank.

56. World Data Atlas, (2020, April 9th). Knoema.com. Retrieved from Kenya - Adult (15+) literacy rate: https://knoema.com/atlas/Kenya/topics/Education/Literacy/Adultliteracy-rate 
57. WHO, (2009). Bulletin of the World Health Organization. Retrieved from World Health Organisation: http://www.who.int

58. WHO, (2019). Progress Towards the SDGs: A Selection of Data from World Health Statistics 2018.

https://www.who.int/gho/publications/world_health_statistics/2018/E N_WHS2018 SDGhighlights.pdf 